\title{
Isolation and Antimicrobial Sensitivity Testing of Escherichia coli from Fish Meat Retailing Shops of Mekelle City, Ethiopia
}

\author{
Awot Teklu $^{1 *}$, Tehetna Alemayhu ${ }^{2}$, Shishay Assefa ${ }^{3}$, Belayneh Getachew ${ }^{2}$, Yohannes \\ Hagos $^{4}$, Tsegay Tkue ${ }^{1}$, and Netsanet Berhe ${ }^{4}$ \\ ${ }^{1}$ Department of Veterinary Theriogenology and Welfare, College of Veterinary Sciences, \\ Mekelle University, P.O. Box 2081, Mekelle, Ethiopia (*awot.teklu@mu.edu.et; \\ awetina95@yahoo.com). \\ ${ }^{2}$ Department of Veterinary Public Health and Food Safety, College of Veterinary Sciences, \\ Mekelle University, P.O. Box 2081, Mekelle, Ethiopia. \\ ${ }^{3}$ Tigray Bureau of Agriculture \& Rural Development Shire District, Shire Endaselassie, Ethiopia. \\ ${ }^{4}$ Department of Veterinary Clinical Medicine and Epidemiology, College of Veterinary Sciences, \\ Mekelle University, P.O. Box 2081, Mekelle, Ethiopia.
}

\begin{abstract}
The present study was conducted for the period of six months, September, 2016 to February, 2017 so as to isolate and identify Escherichia (E.coli) from fresh fish samples collected from four different retailing shops in Mekelle city and determine the antibiotic resistance pattern of isolated bacteria. Isolation and identification of E.coli and antibiotic sensitivity test were performed following the standard microbiological techniques. The antibiotic resistance patterns of the E.coli isolates were tested against 6 different antibiotics, namely Ampicillin, Amoxicillin, Ciprofloxacin, Norfloxacin, Gentamicin and Streptomycin. Accordingly, out of the total 96 fish samples collected and analyzed, 9(9.4\%) were positive for E.coli following the primary and secondary biochemical test results. Out of the four fish meat retailing shops, the highest and statistically significant prevalence $(\mathrm{P}=0.001)$ of E.coli was recorded in shop III as $5(20.8 \%)$ followed by shop II as $4(16.7 \%)$.Furthermore, results of the antimicrobial sensitivity test have shown that all of the isolates were completely significantly $(\mathrm{P}=0.001)$ resistant to two antibiotics (Ampicillin and Amoxicillin) and $100 \%$ significantly susceptible $(\mathrm{P}=0.001)$ to three of the antibiotics (Ciprofloxacin, Norfloxacin, and Gentamicin). Whereas, out of the 9 isolates, 2 isolates $(22.2 \%)$ were intermediate and 7 isolates $(77.8 \%)$ were susceptible to Streptomycin. Hence, it can be concluded that fishes from Mekelle shops do contain antimicrobial resistant pathogenic E.coli where the proportion of these isolates significantly $(\mathrm{P}<0.001)$ varies from shop to shop. In spite of the lesser practice of their utilization, Ciprofloxacin, Norfloxacin, and Gentamicin were found to be the best antimicrobials to treat E.coli associated infections in the study area. However, it is suggested that post-harvest hygienic management practices are to be practiced along the fish production-marketing chain.
\end{abstract}

Keywords: Antibiotic sensitivity test, Escherichia coli, Fish, Mekelle, Retailing shops.

\section{INTRODUCTION}

Fish and fishery products are generally regarded as high risk commodities in respect of pathogen contents and other possible contaminants. Biological contaminants such as bacteria constitute the 
major cause of food-borne diseases. These products are susceptible to a wide variety of potentially pathogenic bacteria and are major vehicles for transmission of several bacterial diseases (Maysoon, 2014). The degeneration of quality of fish is accelerated by microorganisms associated with aquatic environment as well as contamination during post-harvest handling. Poor sanitation and hygiene lead to cross contamination and multiplication of microorganisms and hence poor quality fish are presented to consumers (Jhonstone et al., 1994). Food contamination of antimicrobial-resistant bacteria could be a major public health threat, as the antibiotic resistance determinants can be transferred through the pathogenic bacteria causing compromise in the treatment of severe infections. The prevalence of antimicrobial resistance among foodborne pathogens has increased during recent decades (Rowe-Magnus et al., 2002). Escherichiacoli strains, in particular are candidate vehicles for such problem, not only due to their diversity but also because they exist as common micro-flora of the gastrointestinal tracts of humans and animals (Clements et al., 2012).

In Ethiopia, numerous studies have focused on antimicrobial resistance patterns and genes in E.coli strains isolated from various sources, including food and animals (Birhanu et al., 2008; Yared et al., 2009). However, very few studies focused on isolation of E.coli from fish. Therefore, the objective of this study was to isolate E.coli from fish samples sold in retailing shops of Mekelle city and to perform antibiotic sensitivity test on the isolated E.coli.

\section{MATERIALS AND METHODS}

\subsection{Description of the Study Area}

Mekelle is the capital city of Tigray region, Northern Ethiopia and it is one of the six largest cities of the country located at $39^{0} 29^{1} \mathrm{E}$ and $13^{0} 30^{1} \mathrm{~N}$ latitude and longitude at a distance of 783 $\mathrm{Km}$ north of the capital Addis Ababa. The mean annual rainfall of the city is $628.8 \mathrm{~mm}$, with annual minimum and maximum temperatures of 11.8 and $29.9^{\circ} \mathrm{C}$, respectively (TBARD, 2009). According to the reports of Central Statistical Agency (CSA, 2007), the city has a total population of 215,546 with different feeding habits. Fish is normally consumed in the city with the highest consumption frequency on the fasting days of the Orthodox religion followers. Despite of the low supply, the city receives its raw fish from nearby sources of Lakes Hashenge, Hayk, and Bahir dar as well as from the fishermen associations along the Tekeze River (Asgedom et al., 2012). 


\subsection{Sample Size and Sampling Technique}

Following a prior assessment for fish meat retailing shops in Mekelle city, it was found that there are several restaurants involved in selling processed cooked fish-meat, however, there are only fewer shops of about 5-6 involved in vending whole-raw and filleted fish-meat in the city. Out of these, only four shops were considered in the current study based up on willingness of the owners to participate in the study. It has been observed that, there was low and intermittent supply of fish to these shops and fish may not be available all the time for sale. Hence, technically, one visit was made every month and four fish samples were randomly collected from each shop for a period of six months from November, 2016 to April, 2017

\subsection{Sample Collection and Handling}

A total of 96 fish samples were collected from four fish-meat retailing shops in Mekelle city. Approximately, $30 \mathrm{~g}$ of raw fish-meat samples were collected in sterile polythene zipper pack and transported to Microbiology laboratory of the College of Veterinary Medicine, Mekelle University using an ice box and stored at $4{ }^{\circ} \mathrm{C}$ until they are further processed. All samples were processed for E.coli isolation within $24 \mathrm{hrs}$ of collection.

\subsection{Bacterial Isolation and Identification}

Isolation and Identification of E.coli was performed following the standard microbiological technique as recommended by Quinn et al. (2011). In brief, fish microbial samples were collected using swabs from different parts of the fish (the skin, gills and other relevant body parts of the fish) and aseptically streaked on nutrient agar plates. Bacterial growths were identified and recorded following 24-48 hours incubation at $37^{\circ} \mathrm{C}$ aerobically and a gram staining was performed according to the method described by Quinn et al. (2011). Then, a single isolate colony was picked and streaked on Mac Conkey agar (Oxoid,UK) plates (Carter et al., 1991). The Pink colored colonies observed after incubation were considered as presumptive for E.coli. A single isolated colony was picked and streaked on eosin methylene blue Agar medium (EMB) (Oxoid, USA) and incubated for 24hours. Innocula with a characteristic metallic-sheen on EMB agar medium were considered positive for E.coli. Such colonies were taken and added into nutrient broth for further use.

Furthermore, biotechnical tests were performed as confirmatory tests for E.coli using Oxidase, Indole, methyl red, voges-proskauer, nitrate reduction, citrate utilization, and urease production tests according to Thaker et al. (2012). 


\subsection{Antimicrobial Susceptibility Test}

The antimicrobial susceptibility test was done by agar disc diffusion assay as described by the Clinical and Laboratory Standards Institute (CLSI, 2000). For susceptibility testing, a pure culture of identified E.coli colonies was taken from nutrient agar and transferred into a test tube containing $5 \mathrm{ml}$ of a sterile saline solution and mixed gently to make a homogenous suspension. A cotton swab was used to strike the bacteria across the surface of Muller Hinton agar and wait for about three minutes to dry. Antibiotic discs were then placed on the cultured agar surface using a clean and sterile forceps. The antimicrobial agents used in the current study were Ampicillin (AMP), Amoxicillin (AMC), Gentamicin (GEN), Streptomycin (STR), Ciprofloxacin (CIP) and Norfloxacin (NOR). Following this, plates were aerobically incubated at $37^{\circ} \mathrm{C}$ for 24 hours. Finally, the diameters of the zone of inhibition around the discs were measured to the nearest $\mathrm{mm}$ using a digital electronic caliper and the isolates were classified as susceptible, intermediate, and resistant to the drugs tested according to the interpretation standards of CLSI (2000).

\subsection{Observational Study}

A conjoint observational study was also conducted using a separately developed format. Observations such as educational and professional backgrounds of fish-meat retailers, status of retaining shops including product handling methods, storage systems of different incoming stocks or fish product batches, keeping conjoint edible products such as chicken, beef and others in same refrigerator, and others has been observed and documented from the individual shops visited during sample collection.

\subsection{Data Analysis}

The outcomes of the study were entered into a Microsoft excel program spread sheet and analyzed using SPSS statistical software (version 16). Descriptive statistics were computed and expressed in terms of frequency and percentages. The Fisher's exact test and Chi square values were used to compute results between percentages and P-values $<0.05$ were used as point to assess for any significant difference between variables.

\section{RESULTS}

In the current study, out of a total of 96 fish samples collected from four Fish shops which are found in Mekelle city, 9(9.4\%) samples were positive for E.coli. The highest prevalence of E.coli 
isolates were recorded in shop III (20.8\%). However, all the samples collected from shop I (24) and IV (24) were found to be negative for the pathogenic E.coli. Moreover, it was found that there was a statistically significant difference $(\mathrm{P}=0.001)$ in prevalence of E.coli among the shops (Table 1).

Table1. Percentage of E.coli isolated from fish samples of four different shops in Mekelle city.

\begin{tabular}{|llll|}
\hline Shops & $\begin{array}{l}\text { Total Samples } \\
\text { Collected }\end{array}$ & $\begin{array}{l}\text { Number of Positive } \\
\text { Samples }\end{array}$ & $\begin{array}{l}\text { Percent of Positive } \\
\text { Samples (\%) }\end{array}$ \\
\hline Shop I & 24 & 0 & 0.0 \\
\hline Shop II & 24 & 4 & 16.7 \\
\hline Shop III & 24 & 5 & 20.8 \\
\hline Shop IV & 24 & 0 & 0.0 \\
\hline Total & 96 & 9 & 9.4 \\
\hline
\end{tabular}

For the confirmation of E.coli isolates, biochemical tests were employed on positive culture isolates. Accordingly, results of biochemical tests have confirmed the presence of an indole splitting, acid producing, and nitrate reducing gram negative bacteria of the species Escherichia coli (Table 2).

Table 2. Confirmatory results of biochemical tests for the species Escherichia coli isolated from fish samples.

\begin{tabular}{|clcl|}
\hline No. & Biochemical tests & Results & Characteristic Appearance \\
\hline 1 & Indole & + & Reddish coloration \\
\hline 2 & Methyl red & + & Stable reddish coloration \\
\hline 3 & Nitrate reduction & + & Reddish coloration \\
\hline 4 & Voges-proskauer & - & Absence of red coloration \\
\hline 5 & Citrate utilization & - & Absence of deep blue coloration \\
\hline 6 & Urease production & - & Absence of red/pink coloration \\
\hline 7 & Oxidase & - & Absence of dark blue coloration \\
\hline
\end{tabular}

Table 3.The antibiotic sensitivitypatterns of the E.coli isolates from fish shops in Mekelle (N=9).

\begin{tabular}{|llllllll|}
\hline $\begin{array}{l}\text { Code } \\
\text { number }\end{array}$ & $\begin{array}{l}\text { Antibiotic } \\
\text { name }\end{array}$ & $\begin{array}{l}\text { Break } \\
\text { point }\end{array}$ & Number & $\% \boldsymbol{~}$ & $\boldsymbol{\% I}$ & $\boldsymbol{\% S}$ & $\begin{array}{l}\boldsymbol{\%} \boldsymbol{R} \\
\mathbf{9 5 \% C . I .}\end{array}$ \\
\hline AMP_ND10 & Ampicillin & $14-16$ & 9 & 100 & 0 & 0 & $62.9-100$ \\
\hline AMC_ND20 & Amoxicillin & $14-17$ & 9 & 100 & 0 & 0 & $62.9-100$ \\
\hline GEN_ND10 & Gentamicin & $13-14$ & 9 & 0 & 0 & 100 & $0.0-37.1$ \\
\hline STR_ND10 & Streptomycin & $12-14$ & 9 & 0 & 22.2 & 77.8 & $0.0-37.1$ \\
\hline CIP_ND5 & Ciprofloxacin & $16-20$ & 9 & 0 & 0 & 100 & $0.0-37.1$ \\
\hline NOR_ND10 & Norfloxacin & $13-16$ & 9 & 0 & 0 & 100 & $0.0-37.1$ \\
\hline
\end{tabular}


The sensitive, intermediate and resistance patterns of the nine E.coli isolates from shop II and shop III samples against six tested antibiotics were computed in the study. As a result, out of the total nine E.coli isolates examined in this study, all of them showed resistance against two antibiotics (Ampicillin and Amoxicillin),100\% susceptible for three antibiotics (Gentamicin, Ciprofloxacin, and Norfloxacin). Moreover, $22.2 \%$ and $77.8 \%$ of the isolated E.coli were intermediate and susceptible for Streptomycin, respectively (Table 3).

\section{DISCUSSION}

Out of a total of 96 samples tested for E.coli, 9(9.4\%) of the study fish samples were positive. This finding indicates the contamination of fish with E.coli in Mekelle fish market similar to other researchers' findings in different areas. Thampuran et al. (2005) have isolated E.coli in finfish samples acquired at the retail market in Cochin India. Marin et al. (2009) detected E.coli when researching the bacteriological quality of Cynoscionsquamipinnis and Lutjanusgutattus fish samples marketed in Costa Rica. Similarly, Koo and his coworkers (2012) have also isolated E.coli from rockfish sold in South Korea, and alerting to the presence of E.coli pathogen in seafood.

The highest percentage of E.coli isolates was recorded in shop III 5(20.8\%) followed by shop II 4(16.7\%). However, all the samples collected from shop I and IV was negative for E.coli. The difference between these shops might be due to the education level of shop owners and the shop status. Shop I and IV owners are educated and these shops sold only raw fish. Regarding, the storage system, they have different refrigerators for storage of each week stocks; they keep different batches of fishes separately. However, shops II and III owners are uneducated and the shops are not only fish shop; they also supply ready to eat foods from different meat products. Moreover, these shops only have single refrigerator which is used for storage of all fishes purchased in different time periods. These may indicate the possible cross contamination of the samples with different meat products of other animals (Chicken and beef) through hands of the seller or equipment.

All the nine isolates were 100\%resistant for two antibiotics, Ampicillin and Amoxicillin. This result showed that these are the most commonly used antibiotics and results in antimicrobial resistance in the study area. While, this study did not investigate the mechanisms underlying the development of antimicrobial resistance in these E.coli isolates, several previous studies have 
established a causal relationship between antimicrobial use in aquaculture and the increase in specific antimicrobial-resistant bacterial strains (Schmidt et al., 2001; Petersen et al., 2002; Ribeiro et al., 2010; Ye et al., 2013). The use of antibiotic in aquaculture was confirmed by different researchers. Agreeably, the World Health Organization (WHO) has reported the use of many antibiotics for therapeutic treatment and prophylactic purposes in fish; consequently, have stated that the increase in antimicrobial resistance due to excess use and misuse of antimicrobials is a public health concern (WHO, 2001). The results of this study agree with the finding of Immaculate et al. (2012) who have performed antibiotic sensitivity test on E.coli isolates from sea foods such as fin fishes and found considerable levels of resistance against Amoxicillin (47\%) and Ampicillin (34\%). Similarly, Ryu et al. (2012) also found Ampicillin resistance E.coli isolates from fish collected from wholesale and retail markets in Seoul, Korea. While, KwonSam, (2013) have found some level of resistance to Ampicillin (22.1\%), Streptomycin (11.5\%), Norfloxacin (6.1\%), Ciprofloxacin (2.3\%), and Gentamicin (0.8\%) on E.coli isolated from fishes in the Gomso Bay. However, this result disagree with the findings of Soliman et al. (2010) who found Ampicillin susceptible E.coli isolates from cultured freshwater fish.

In the present study, the antibiotics Ciprofloxacin, Norfloxacin and Gentamicin were proved to be the best antibiotics for the treatment of E.coli infection since they were highly effective. In agreement with these findings, Immaculate et al. (2012) who have performed antibiotic sensitivity test on E.coli isolated from sea foods such as fin fishes found considerable levels of susceptibility against Ciprofloxacin (91\%) and Gentamicin (78\%).

\section{CONCLUSION}

The present study revealed that E.coli is a contaminant of fish in the study area and its occurrence in fish could represent a risk to the consumers. There is a difference in the occurrence of E.coli between fish shops due to lack of awareness among shop owners and attendants about strict hygienic measures to avoid pathogenic contamination of fish at various stages of production, storage and transportation to safeguard the public health. Furthermore, it revealed that fish from Mekelle shops contains antibiotic resistant E.coli strains. The result warned the need for more strict preventive measures such as regular washing and sterilization of equipment, utensils, and handler hands starting from the point of production to consumption. However, a 
detail scientific study should be conducted to further elaborate the source of contamination along the production-consumption chain of fish.

\section{ACKNOWLEDGEMENTS}

The author and his coworkers would like to express their thanks to Mekelle University, Research directorate for funding the research work through recurrent budget. Special thanks also go to the College of Veterinary Medicine for allowing us to use the laboratories and necessary equipments as well. Finally we would like to thank the Fish-meat retailing shops of Mekelle city for their voluntariness and collaborations throughout the research work.

\section{CONFLINCT OF INTEREST}

There are no conflicts of interests.

\section{REFERENCE}

Asgedom, A.G., Desta, M.B \& Gebremedhin, Y.W. 2012. Bioaccumulation of Heavy Metals in Fishes of Hashenge Lake, Tigray, Northern Highlands of Ethiopia. American Journal of Chemistry, 2(6): 326-334.

Birhanu, H., Etsay, K \& Hailay, K. 2008. Assessment of bacteriological quality of raw camels' milk in Ab-'Ala, north eastern Ethiopia. Livestock Research for Rural Development. 20:44-65.

Carter, G.R., Chengappa, M.M \& William, G. 1991. Essentials of Veterinary Bacteriology and Mycology. $4^{\text {th }}$ edition, Philadelphia, London, 109p.

Clements, A., Young, J.C., Constantinou, N \& Frankel, G. 2012. Infection strategies of enteric pathogenic Escherichia coli. Gut Microbes, 3:71-87.

CLSI. 2000. Clinical and Laboratory Standards Institute: Performance standards for antimicrobial susceptibility testing. CLSI document M100-S20. Clinical and Laboratory Standards Institute, Wayne, PA. US.

CSA. 2007. The Central Statistical Agency country summary, Ethiopia. Agriculture in Figures: Key findings of the 2008/09-2010/11 agricultural sample surveys for all sectors and seasons, Addis Ababa. pp. 55-57. 
Immaculate, J. K., Velammal, A \& Jamila, P. 2012. Prevalence of Antibiotic Resistant Escherichia coli in Sea Foods of Tuticorin Coast, Southeastern India. Suganthi Devadason Marine Research Institute. Tamil Nadu, India. 70p (unpubl.).

Jhonstone, W.A., Nicholason, F.J., Roger, A \& Stroud, G.D. 1994. Freezing and refrigerate storage in fisheries, Rome, Italy. Technical paper, No. 334: 143.

Koo, H.J., Kwak, H.S., Yoon, S.H \& Woo, G.J. 2012. Phylogenetic group distribution and prevalence of virulence genes in Escherichia coli isolates from food samples in South Korea. World Journal of Microbiology and Biotechnology, 28: 1813-1816.

Kwon-Sam, P. 2013. Antimicrobial Resistance and Virulence Genes Presence in Escherichia coli Strains Isolated from Gomso Bay, Korea. Department of Food Science and Biotechnology, College of Ocean Science and Technology, Kunsan National University, Gunsan Korea. Fisheries and aquatic science, 16(4): 221-227.

Marín, C., Fonseca, C., Arias, S., Villegas, I., García, A \& Ishihara, H. 2009. Bacteriological load of the fishes Cynoscionsquamipinnis and Lutjanusgutattus in the marketing chain, Costa Rica. Revista de Biología Tropical, 57: 45-52.

Maysoon, S. A. 2014. Isolation of bacteria from fish. Veterinary Medicine University of Baghdad, Iraq. International Journal of Advanced Research, 2: 274-279.

Petersen, A., Andersen, J.S., Kaewmak, T., Somsiri, T \& Dalsgaard, A. 2002. Impact of integrated fish farming on antimicrobial resistance in a pond environment. Applied Environmental Microbiology, 68: 6036-6042.

Quinn, P.J., Markey, B.K.F., Leonard, C., Hartigan, P., Fanning, S \& Fitzpatrick, E.S. 2011. $A$ Text book of Veterinary Microbiology and Microbial Disease. Wiley-Blackwell Publishers. pp. 123-146.

Ribeiro, R.V., Reis, E.M.F., Reis, C.M.F., Freitas, A.A.C \& Rodrigues, D.P. 2010. Incidence and antimicrobial resistance of enteropathogens isolated from an integrated aquaculture system. Lett. Appl. Microbiol., 51: 611-618.

Rowe-Magnus, D.A., Guerout, A.M \& Mazel, D. 2002. Bacterial resistance evolution by recruitment of superintegron gene cassettes. Molecular Microbiology, 43: 1657-1669.

Ryu, S.H., Park, S.G., Choi, S.M., Hwang, Y.O., Ham, H.J., Kim, S.U., Lee, Y.K., Kim, M.S., Park, G.Y., Kim, K.S \& Chae, Y.Z. 2012. Antimicrobial resistance and resistance genes 
in Escherichia coli strains isolated from commercial fish and seafood. International Journal of Food Microbiology, 152: 14-18.

Schmidt, A.S., Bruun, M.S., Dalsgaard, I \& Larsen, J.L. 2001. Incidence, distribution and spread of tetracycline resistance determinants and integron-associated antibiotic resistance genes among motile aeromonads from a fish farming environment. Applied Environmental Microbiology, 67: 5675-5682.

Soliman, M.K., Khalil, R.H., Saad, T.T., El-Gamal, M.H.L \& Gebril, A.E. 2010. Isolation and Identification of E.coli from Cultured Freshwater Fish. Journal of the Arabian Aquaculture Society, 5(1): 19-34.

TBARD. 2009. Tigray Bureau of Agriculture and Rural Development. Estimated livestock population of the Tigray Regional State. pp. 166-171.

Thaker, H.C., Brahmbhatt, M.N \& Nayak, J.B., 2012. Study on occurrence and antibiogram pattern of Escherichia coli from raw milk samples in Anand, Gujarat, India. Veterinary World, 5(9): 556-559

Thampuran, N., Surendraraj, A \& Surendran, P.K. 2005. Prevalence and characterization of typical and a typical Escherichia coli from fish sold at retail in Cochin, India. Journal of Food Protection, 68: 2208-2211.

WHO. 2001. The World Health Organization: Global Strategy for Containment of Antimicrobial Resistance. Publication nr WHO/CDS/CSR/DRS/2001.2a, World Health Organization, Geneva. pp. 201-220.

Yared, H.M., Huisman, E.A \& Machiels, M.A. 2009. Reducing Postharvest Fish Loses in Selected Lakes of Ethiopia. Project of the NAHDIC research center, Sebeta, Ethiopia.

Ye, L., Lu, Z., Li, X., Shi, L., Huang, Y \& Wang, H.H. 2013. Antibiotic resistant bacteria associated with retail aquaculture products from Guangzhou, China. J. Food Prot., 76: 295-301. 